\title{
Larval fishes utilize Batesian mimicry as a survival strategy in the plankton
}

\author{
Adam T. Greer ${ }^{1,4, *}$, C. Brock Woodson ${ }^{1}$, Cedric M. Guigand ${ }^{2}$, Robert K. Cowen ${ }^{3}$ \\ ${ }^{1}$ College of Engineering, University of Georgia, Athens, GA 30602, USA \\ ${ }^{2}$ Rosenstiel School of Marine and Atmospheric Science, University of Miami, Miami, FL 33149, USA \\ ${ }^{3}$ Hatfield Marine Station, Oregon State University, Newport, OR 97365, USA \\ ${ }^{4}$ Present address: Department of Marine Science, University of Southern Mississippi, 1020 Balch Boulevard, \\ Stennis Space Center, MS 39529, USA
}

ABSTRACT: Marine teleost fishes often experience over $99 \%$ mortality in the early life stages (eggs and larvae), yet larval survival is essential to population sustainability. Marine fish larvae from a wide range of families display elaborate, delicate features that bear little resemblance to adult forms and hinder their swimming escape ability by increasing drag. Here, we systematically examine the criteria needed for Batesian mimicry to evolve as a survival strategy and present new evidence from in situ imaging technology and simulation modelling to support the hypothesis that many larval morphological features (particularly long, delicate fin rays) and behaviors evolved at least in part through Batesian mimicry of less palatable or noxious gelatinous zooplankton. Many of these organisms (e.g. hydromedusae, ctenophores, and siphonophores) are much more abundant than previously recognized. The high predation mortality during the larval phase provides strong potential for selection in favor of maintaining complex and metabolically costly features that mimic gelatinous zooplankton, provided that larger fishes, as selective visual predators, can occasionally be fooled. We conclude that recent advances in our understanding of mimicry combined with information obtained from plankton imaging supports the hypothesis that Batesian mimicry is a widespread survival strategy for larval fishes, which could have broad implications for fish population dynamics. However, further research is needed in the areas of predator cognition and larval fish behavior in the presence of different predators and models to elucidate the circumstances in which the larval fish mimicry hypothesis may apply.

KEY WORDS: Batesian mimicry $\cdot$ Larval fish · Gelatinous zooplankton $\cdot$ Survival $\cdot$ Recruitment $\cdot$ Plankton

\footnotetext{
*Corresponding author: adam.t.greer@gmail.com
}

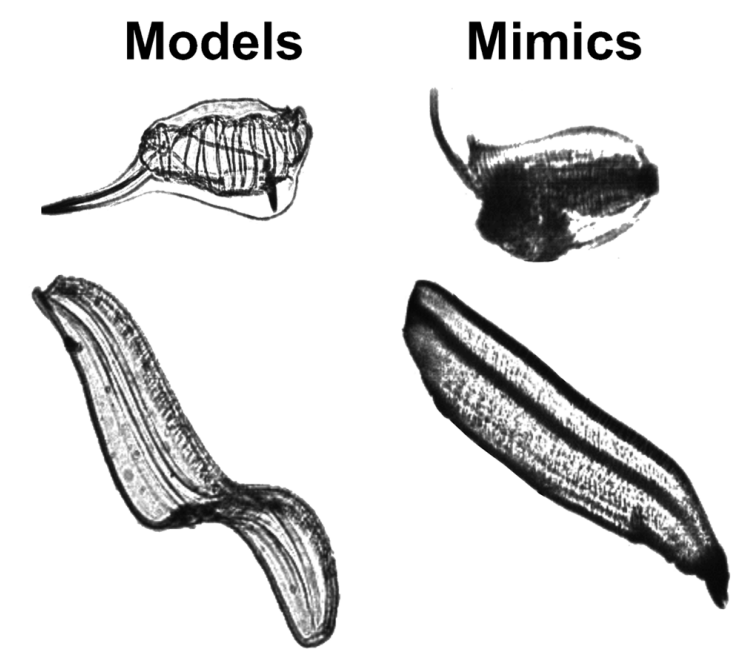

Shadowgraph images of potential gelatinous zooplankton models (top: salp; bottom: cestid ctenophore) and corresponding larval fish mimics (top: bothid larva; bottom: leptocephalus larva).

\section{INTRODUCTION}

A vast majority of marine fishes begin their lives as microscopic eggs, which then hatch into small $(\sim 2 \mathrm{~mm})$ larvae and, over the course of weeks to months, grow to several centimeters in size as members of drifting plankton communities. Under typical circumstances, between one in a thousand and less than one in a million of these larvae survive to recruit to adult habitats, with most lost through predation (starvation and disease can also play a role, depending on environmental conditions; Houde 2002, Govoni 2005). Therefore, slight changes in survival rate of lar-

(C) The authors 2016. Open Access under Creative Commons by Attribution Licence. Use, distribution and reproduction are unrestricted. Authors and original publication must be credited. 
vae can have a huge impact on the abundance of the next generation of juveniles and fisheries production in subsequent years (Hjort 1914). In ecological communities, predation is typically minimized through avoidance, escape capability (swimming), direct defenses (mechanical or chemical), crypsis, or mimicry (Ohman 1988, Johnsen 2014). It is generally believed that the primary survival option available to marine fish larvae is fast growth to minimize their exposure to predators and quickly enhance swimming capabilities (Houde 1987, Anderson 1988, Bailey \& Houde 1989, Hare \& Cowen 1997), since larvae are not well defended against faster predators (Connell 2000, Govoni 2005) and often appear quite conspicuous (at a minimum, they are unable to be completely transparent).

Although the phenotype of an individual fish larva has little effect on where it is spawned and the food concentrations it encounters in its environment, the larval fish phenotype can potentially have a large impact on predation through deception or direct defenses against predators. Larval fishes have extremely diverse and complex morphologies, even withinfamily (Moser 1981, Webb 1999, Miller \& Kendall 2009), which is in direct contrast to the similarly sized adult copepods, a group that contains many distantly related taxa that have a wide range of feeding modes, yet converge on a similar body shape optimized for quick escape responses (Kiørboe 2008). If a similar selective pressure was optimizing fish larvae for fast escape responses, then we would expect larval fish morphologies to converge on a particular body shape, as has occurred in copepod morphology. The diversity of larval fish morphologies suggests different predation reducing strategies are operating, even though visual predation by larger fishes is likely the dominant selective force for both larval fishes and copepods (Bailey \& Houde 1989, Houde 2002). Here, we seek to explore the idea that the diversity of larval fish morphologies arises from a spectrum of antipredator strategies, with 2 extremes characterized by long spines to mechanically deter predators or delicate fin rays and partial transparency to visually deceive them. In both cases, there is a potential fitness benefit to resembling a common zooplankter that is noxious or less nutritionally valuable to a predator. However, there may be multiple explanations for why larvae exhibit particular morphological features.

Batesian mimicry describes how an otherwise palatable mimic receives protection by imitating a model that is distasteful or noxious to a predator (Bates 1862). While Batesian mimicry can apply to any sensory system (Ruxton et al. 2004), it is most thoroughly studied with regards to vision. Mimics can display conspicuous features that indicate to a predator that they are noxious or simply less energetically profitable to consume. Batesian mimicry is most often studied in terrestrial systems, but it has also been documented in marine habitats, particularly on coral reefs (Caley \& Schluter 2003, Côté \& Cheney 2005, Randall 2005). For visual Batesian mimicry to evolve with regard to larval fishes and different types of zooplankton, 3 criteria are typically met (Huheey 1988, Caley \& Schluter 2003): (1) visual predation must be a strong source of mortality; (2) there is a relatively abundant and unpalatable (or undesirable) model that the mimic resembles through morphology or behavior; and (3) mimicry must provide an 'umbrella' of protection, whereby mimics with only a slight resemblance to the model receive some degree of protection. However, the extent of this 'umbrella' can vary greatly depending on predator visual acuity and the toxicity of the model (Caley \& Schluter 2003, Ruxton et al. 2004).

To explore the evidence for these criteria, we drew on simulation modelling and new data from in situ imaging to show the diversity of gelatinous zooplankton shapes and the larval fishes that resemble them through both morphology and behavior. To address the first 2 criteria, we used in situ imaging technology to describe larval fish live appearance, abundance, and orientation (Cowen \& Guigand 2008, Greer et al. 2013), which we compared to potential models in the vicinity. Small gelatinous zooplankton $(<5 \mathrm{~cm})$ have been historically difficult to sample due to their fragility and destruction in plankton nets (Hamner et al. 1975), but studies using imaging technology have shown that gelatinous zooplankton within the size range of larval fishes are extremely abundant (Remsen et al. 2004, Greer et al. 2014, Luo et al. 2014) and could serve as potential models because they are avoided by many pelagic consumers due to their high water content, relatively low carbon content, and, in cnidarians, stinging nematocysts (Hamner et al. 1975, Purcell \& Arai 2001, Bullard \& Hay 2002). For the final criterion, we used a numerical simulation to show that complex and metabolically costly phenotypes can evolve quickly with only a miniscule advantage for larval fish survival. The use of mimicry could be a mechanism of population stability and potentially explain why larval survival may be higher than once thought (White et al. 2014). An additional goal of this research is to stimulate further investigations into the phenomenon of Batesian mimicry in the plankton and other potential mechanisms of larval survival, leading to improvement in the understanding and predictability of fish population dynamics. 


\section{MATERIALS AND METHODS}

Images of larval fishes and their zooplankton models for mimicry were collected using the In Situ Ichthyoplankton Imaging System (ISIIS; Cowen \& Guigand 2008). ISIIS uses a backlighting technique to image zooplankton and larval fishes in the size range of $500 \mu \mathrm{m}$ to $13 \mathrm{~cm}$. Details on the imaging technique can be found in Cowen \& Guigand (2008). Data used in this study were from 2 separate research cruises: imagery from the Gulf of Mexico was acquired on the NOAA ship 'McArthur II' during the summer of 2011; Stellwagen Bank and Georges Bank images were collected onboard the NOAA ship 'Delaware II' in August 2010. The analysis involved examining over 1 million images, with classification into approximately 12 taxonomic categories. The larval fish category was classified manually to the family level, with some genus or species level identifications possible in images with particularly good morphological detail.

To address the potential for evolution of mimicry in larval fishes using realistic larval population sizes, we created a numerical simulation in MATLAB (v.R2014a) for a single fish population, where each adult is given a value for 2 traits that are needed for successful mimicry. Initial values of the traits in parents were set using a normally distributed random number generator with a mean of 0 and a standard deviation of 1. Each year, the population released 1 million larvae with trait values derived from the parents. During the larval period, mortality was set to 0.999999. For each trait, this mortality was modified by a survival factor of $1 \times 10^{-8}$ multiplied by the sum of the trait values. Positive (negative) values of both traits were considered beneficial (harmful) by their alteration of the mortality probability. This resulted in a maximum benefit of $1.3 \times 10^{-7}$ for the maximum value of both traits and a minimum mortality rate of 0.9999937 . The mortality rate of adults was set to 0.05 and increased by $0.1 \mathrm{yr}^{-1}$ after age 8 . The model was then run for $5000 \mathrm{yr}$. We also ran a trial where the benefit for Trait 2 was dependent on Trait 1 (Kazemi et al. 2015), as would be the case for the evolution of a behavioral trait following a morphological trait, with an additional 5000 yr $(10000$ yr total). Finally, trials were performed where positive larval traits were linked to negative adult traits, with 100 times greater selection in the adult phase. In other words, a beneficial larval trait had a 100 times stronger negative effect in the adult phase of the life cycle.

While the simulation was used to show the amount of selection needed for mimicry to take hold in a population, it did not incorporate a trade-off between mimicry and growth to a critical size needed for recruitment. To address this trade-off between investment in mimicry and faster growth without defenses, we used a Leslie matrix approach, varying the probability of the 31 to $35 \mathrm{~d}$ stage larval survival (a proxy for mimicry) and the probability of recruitment (a proxy for environmental conditions affecting recruitment). The Leslie matrix population model is a discrete, age-structured population model, and at a certain age class the larva has a certain probability of 'recruiting' to the juvenile stage. These large, late-stage larvae face a critical period whereby fast growth can lead to early recruitment, or the larvae can invest in strategies that increase survival in the plankton and delay recruitment. The Leslie matrix contained 18 larval stages, 3 juvenile stages, and 9 adult stages. For each iteration, the absolute value of the first eigenvalue determined the relative population growth rate with varying recruitment and survival probabilities for the 31 to $35 \mathrm{~d}$ old larvae. All other cells within the Leslie matrix were unaltered. Individuals with lower larval survival (non-mimickers) could recruit one stage earlier in the Leslie matrix, giving them a distinct advantage if probability of recruitment was high. The Leslie matrices (Supplement 1) and model code (Supplement 2) used in the analysis are available at www.int-res.com/articles/suppl1/m551p001_supp.xlsx and www.int-res.com/articles/suppl2/m551p001_supp. txt, respectively.

To demonstrate the common behaviors of vertical orientation of chaetognaths and larval fishes with high aspect ratios (length/width), an image analysis program was implemented in ImageJ (Rasband 2012). This program fitted an ellipse to each larval fish or chaetognath and measured its major and minor axes (and aspect ratio), as well as the angle of orientation of the major axis relative to the center of the ellipse. The angle of orientation results gave a value between 0 and $180^{\circ}$. As the program made no distinction between head-up or -down positioning, the data were transformed to conform to the assumptions of linear statistics using the absolute value of the angle-90. This transformation produced values between 0 and $90^{\circ}$, where $0^{\circ}$ coincided with horizontally orienting zooplankton, and $90^{\circ}$ was directly vertical. Pitch of the imaging system was negligible $\left(<2^{\circ}\right)$ and was therefore not used to correct the angle measurements. The angle values for the larval fishes were analyzed with a linear regression using $\mathrm{R}$ (v.3.2.1; R Core Team 2014), and residuals were normally distributed. 


\section{RESULTS}

The resemblances of different larval fishes to members of the gelatinous zooplankton community are striking when viewing general body shape, transparency, and positioning of fin rays. Gelatinous zooplankton often have long, delicate tentacles that can be readily observed using in situ imaging. These tentacles typically contain pigmented or translucent 'notches' that are budding cormidia or nematocysts in siphonophores and hydromedusae or, in ctenophores, branches that increase cross-sectional area and improve prey capture ability. Many larval fishes have evolved delicate and elaborate fin ray extensions that closely resemble the tentacles of siphonophores and ctenophores, including small swellings that resemble the 'notches' (Fig. 1A-D). In the Liopropoma genus of groupers, these long fin rays have been taken to an extreme, with 2 rays extending several times the body length (Fig. 1D). The general shape and positioning of the dorsal fin ray on many flatfishes resemble salps and the projection of their tunics (Fig. 1E,F). The closest resemblance between fish larvae and gelatinous zooplankton is seen in the leptocephalus larvae that are almost identical to a cestid ctenophore (Fig. 1G,H).

Larval fishes may also enhance their morphological similarity to gelatinous zooplankton through specific behaviors. The leptocephalus larvae sometimes exhibit a curling behavior that resembles the appearance of a salp or doliolid (Fig. 1I).When flatfishes curl, their dorsal fin rays remain extended, allowing them to resemble the abundant goblet medusa Solmundella bitentaculata (Fig. 1J,K). This behavior could be a defense posture triggered by the passing imaging system, or it is an orientation that they happen to display a certain percentage of the time. Elongate larvae tend to orient vertically in a manner similar to chaetognaths (Fig. 1L-N). There is a significant linear relationship between larval fish aspect ratio and their angle of orientation $\left(\mathrm{R}^{2}=0.223\right.$; Fig. 2). In a variety of environments, different groups of small gelatinous zooplankton $(<5 \mathrm{~cm})$ far outnumber larval fishes (Fig. 3).

The simulation models were designed to test whether a trait with a minute advantage for survival could evolve in a large population experiencing extremely high mortality due to both predators (influenced by larval fish phenotype) and environmental conditions (random effects). The model outputs demonstrate that the evolution of traits for larval survival is rapid even with a miniscule effect on the potential survivorship of an individual larva (Fig. 4A,B).
There is also strong selection and rapid evolution for both a morphological and a linked behavioral trait (Fig. 4C,D). In a more extreme scenario, the positive selection is rapid even if the larval traits are linked to a trait with a 100 times stronger negative effect on the survivorship of adults (Fig. 4E,F).

With increasing ability to survive in the plankton (through mimicry or other defenses), populations with larval stages are less dependent on environmental conditions, as depicted by variability in the probability of recruitment (Fig. 5). Through the use of a Leslie matrix, we altered the probability of recruitment to the juvenile phase and survival (staying in the plankton) for late-stage larvae, and saw changes in the population growth rate, as indicated by the absolute value of the first eigenvalue. The populations with high probability of larval survival had stable growth under a range of recruitment probabilities (a proxy for environmental conditions) because of their ability to survive (through mimicry) delayed recruitment. When larvae do not invest in mimicry or defenses (low probability of survival), the population is dependent on favorable environmental conditions to aid in high recruitment, which can easily result in it experiencing recruitment failure. During the 'good' years where recruitment probability is high, populations that do not invest in mimicry can outcompete ones that invest in mimicry, but populations that invest resources into mimicry have more stable recruitment even in the face of poor environmental conditions, as indicated by the right side of the graph, with stable population growth rates across a range of recruitment probabilities.

\section{DISCUSSION}

We suggest that Batesian mimicry is a more widespread survival strategy than previously recognized because many distantly related fish taxa have converged on the production of delicate features, including extremely long fin rays (pleuronectiformes, serranids, gadiformes, lamprids, lophiids), externally trailing guts (myctophids, gadiformes), and even eyes on stalks (myctophids, stomiids) (Moser 1981, Miller \& Kendall 2009). All of these morphological features seem to have a metabolic cost through the maintenance of tissue not associated with skeletal growth and inhibit swimming escape response through increased drag (Baldwin \& Johnson 1993, Okamoto \& Ida 2001). Some morphologies may have multiple benefits (Cheney 2013, Nelson 2014). For example, stalked eyes aid in prey location (Weihs \& 

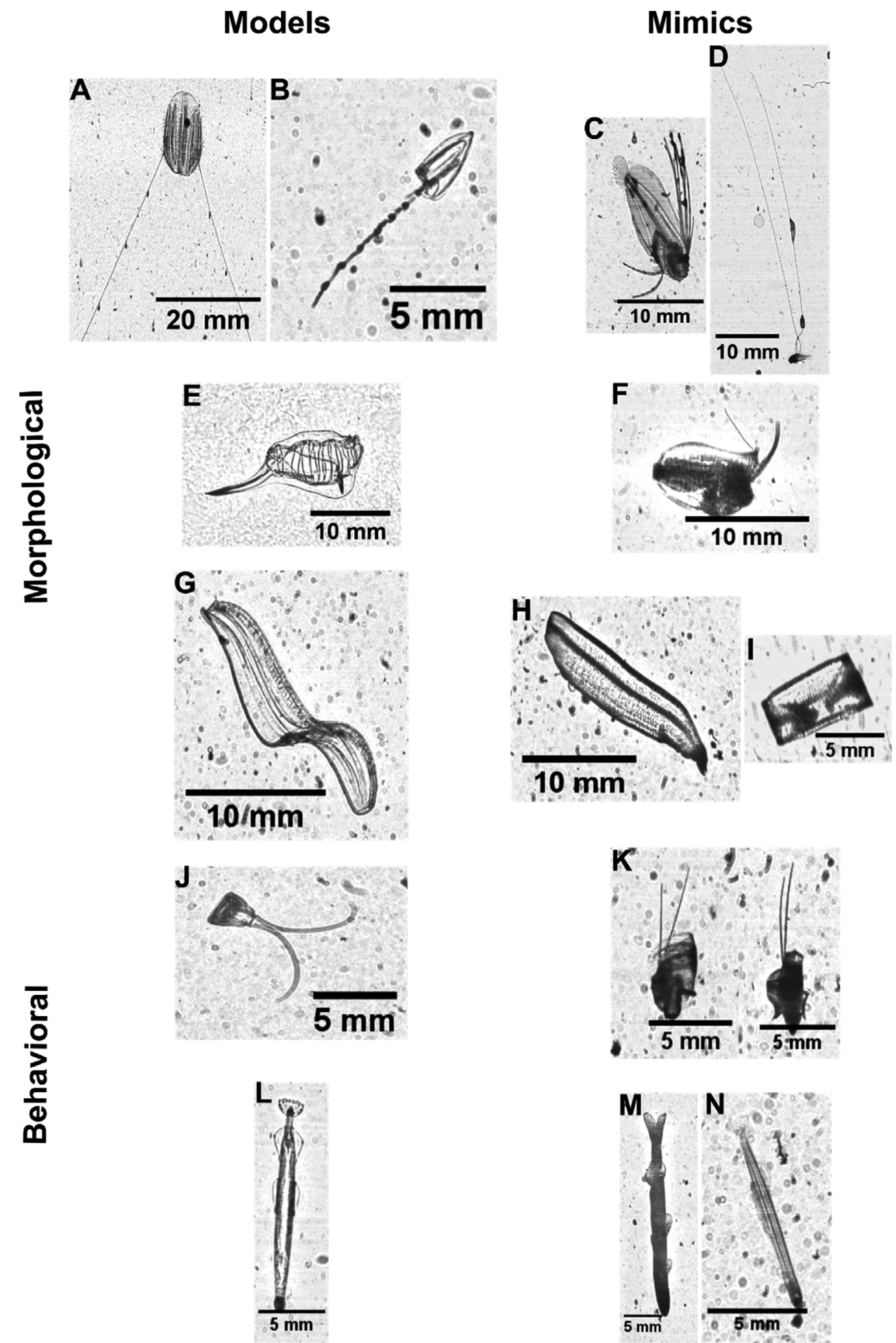

Fig. 1. Example images of morphological and behavioral mimicry showing less palatable models (from the perspective of a visual predator) and corresponding mimics in their natural orientation: (A) ctenophore Euplokamis dunlapae; (B) calycophoran siphonophore; (C) flatfish larvae (Paralichthyidae), note pigmented swellings similar to A and B; (D) grouper larva (Liopropoma spp.), note pigmented swellings similar to $A$ and $B_{i}(E)$ salp (Thalia spp.); (F) flatfish larva (Bothidae); (G) cestid ctenophore; (H) leptocephalus eel larva (Muraenidae); (I) leptocephalus larva in curled posture with similar appearance to a salp; $_{i}(\mathrm{~J})$ narcomedusa Solmundella bitentaculata; (K) flatfish larvae in curled posture; (L) chaetognath (Sagitta spp.); (M) anchovy larva (Engraulidae); and (N) clupeid larva (Clupeidae) vertically orienting. Note changes in scale bars among images 


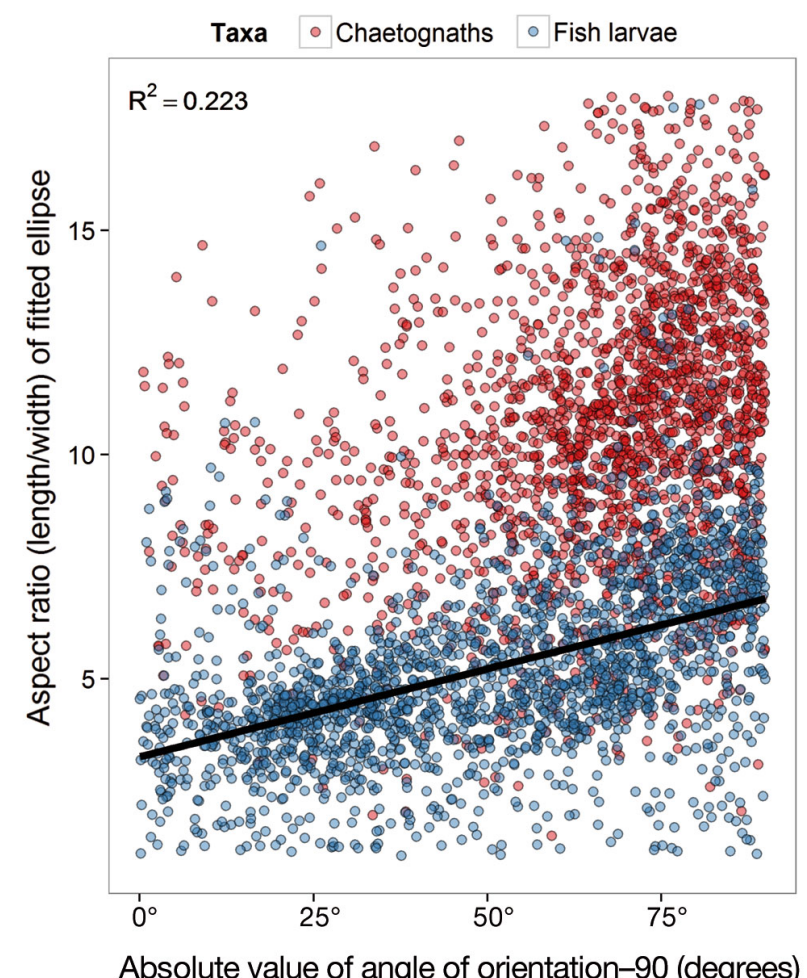

Fig. 2. Vertical angle of orientation of chaetognaths and larval fishes compared to their aspect ratio (length/width of a fitted ellipse). The $x$-axis shows the orientation angle between 0 and $180^{\circ}$ transformed by taking the absolute value of the angle-90. The transformation shows vertically orienting plankton near $90^{\circ}$, and horizontal ones near $0^{\circ}$

Moser 1981), and trailing guts could allow for direct absorption of nutrients (Webb 1999). The morphological resemblance of larval fishes to unpalatable and sometimes noxious gelatinous zooplankton is striking when viewed with in situ imaging, through

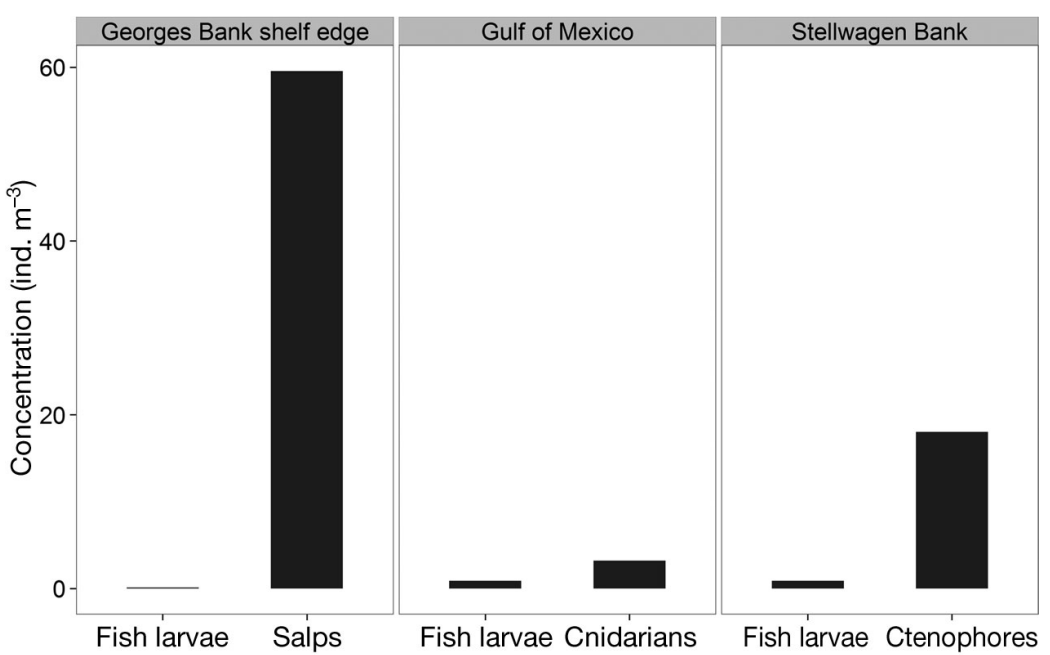

Fig. 3. Concentrations of larval fishes and the dominant gelatinous zooplankton in shallow waters $(<50 \mathrm{~m})$ in 3 locations. Near the Georges Bank shelf edge, larval fishes were rare, with an average concentration of 0.065 ind. $\mathrm{m}^{-3}$ which organisms are sampled in an undamaged state with their natural orientation. Below, we review the evidence relating to the criteria for Batesian mimicry to exist as a survival strategy, and how the results of this study complement our current knowledge of early life history processes. We also discuss potential experiments that could provide more definitive proof that the phenomenon of Batesian mimicry is widespread for the early life stages of fishes.

\section{Evidence for Batesian mimicry}

For Batesian mimicry to be a viable survival strategy in the plankton the first major criterion is that visual predation must be a strong source of mortality. Although larval fishes have a wide range of potential predators (Bailey \& Houde 1989), the strongest predation likely comes from other fishes due to the predators' relatively high metabolic requirements, short prey handling time, and ability to visually target specific individuals for capture over a wide range of sizes. The ubiquity of visual cues in the epipelagic ocean has led to convergent evolution of several mechanisms of crypsis (Hamner 1995, Johnsen 2014), but little attention has been paid to the phenomenon of mimicry in the plankton, other than examples of aggressive mimicry (Purcell 1980, Haddock et al. 2005), behavioral mimicry below depths occupied by a vast majority of larval fishes (Robison 1999), and superficial claims of mimicry based on morphological traits of certain species of fish larvae (Amaoka 1972, Fraser \& Smith 1974, Suntsov 2007).

The second criterion is that there must be a relatively abundant and unpalatable (or undesirable) model that the rarer organism mimics through morphology or behavior (Huheey 1988). Because of their high abundance, similar size to fish larvae, and unpalatability to many predators (Purcell \& Arai 2001, Bullard \& Hay 2002), small gelatinous zooplankton are a good potential model for Batesian mimicry by fish larvae. Many gelatinous defense strategies seem to be aimed at increasing conspicuousness to minimize accidental damage through contact with other organisms (i.e. crumpling and blanching; Mackie 1995). Gelatinous organisms often use 'selfmimicry', meaning their blanching pig- 
Fig. 4. Population distribution of trait values (left panels) and mean trait values over time (right panels) for larval mimicry in model fish populations. Each year is equivalent to 1 generation, and the red and blue lines represent the trait values for 2 traits. A total of 3 separate simulations show $(\mathrm{A}, \mathrm{B}) 2$ unlinked traits needed for mimicry; $(C, D)$ benefit as a result of Trait 2 is dependent on Trait 1 ; and $(\mathrm{E}, \mathrm{F})$ both larval traits linked to traits that are detrimental to adult survival, with selection 100 times greater in adults. Both traits increase larval survival by a maximum of $1 \times 10^{-8}$ and base larval survival is set to $1 \times 10^{-6}$
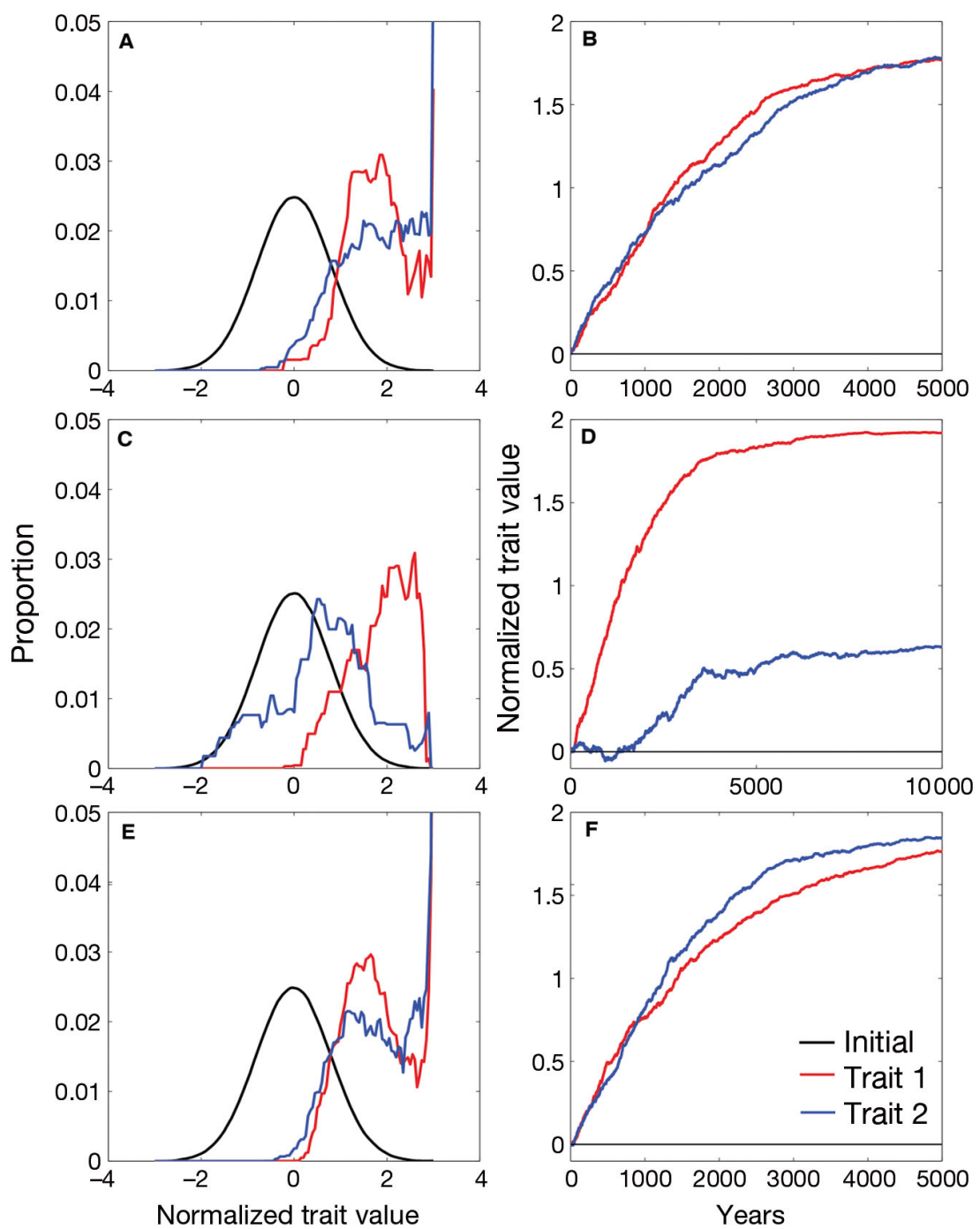

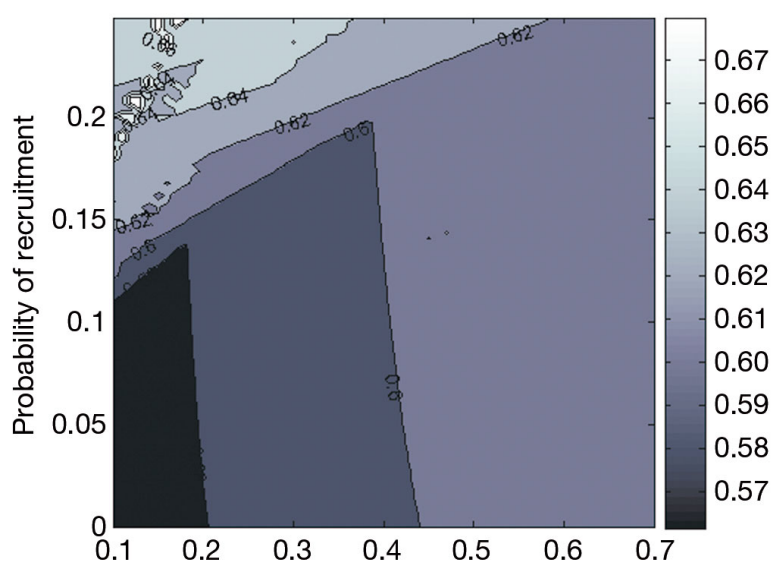

Probability of survival and staying in the plankton

Fig. 5. Leslie matrix analysis showing the absolute value of the first eigenvalue (a proxy for population growth, with higher numbers indicating faster growth) with varying larval survival probabilities and recruitment probabilities for larvae at the first stage in which they can recruit (31 to $35 \mathrm{~d}$ old) ment patterns seen during the day resemble their bioluminescence patterns at night (Mackie 1995). This serves as a versatile warning to visual predators that these fragile organisms should be avoided, and visible communication of unpalatability is clearly an important defense mechanism.

The evidence for larval fish mimicry of gelatinous zooplankton is strong, based on both larval resemblance to and the unpalatability of gelatinous zooplankton, but there may also be advantages to visually resembling non-gelatinous zooplankton. The spines found on many different opaque larvae have typically been attributed to a survival benefit of gape-limiting predation (Moser 1981), but the larval mimicry hypothesis suggests a potential added benefit is the mimicry of less palatable crustacean zooplankton. Indeed, the caloric density of fish larvae is higher than crustacean zooplankton and increases with larval size (Davis et al. 1998, Wuenschel et al. 
2006), so mimicking something less nutritionally valuable could have additional benefits to simply being difficult for predators to handle. The alternative and more widely accepted explanation is that opaque and spiny larval morphology is simply convergent evolution toward common direct defense structures, similar to the way that many unrelated pelagic zooplankton have converged on transparency (McFall-Ngai 1990, Johnsen 2014). However, these explanations may not be mutually exclusive; large spines could deter a predator from making a close approach and provide gape-limited predation if an attack is made. If, indeed, predators cue in on spines or a few other conspicuous features when assessing the palatability of prey (Gamberale-Stille et al. 2012), large spines or other body extensions could reduce the probability of attack, and thus those traits would experience positive selection.

The larval fish morphology spectrum presents trade-offs related to mimicry, direct defenses, and escape response. Research on zooplankton body composition has shown a bimodal distribution of zooplankton with regards to their water and nutritional content, with chaetognaths being one of the only intermediate groups (Bullard \& Hay 2002, Kiørboe 2013; Fig. 6A). The widespread use and variety of mechanisms in maintaining delicate filaments (Govoni et al. 1984) supports the hypothesis of Batesian mimicry of gelatinous zooplankton, while the opposite (opaque larvae with spines) suggests convergent evolution of anti-predator strategies used by crustacean zooplankton, with a potential added benefit of mimicry (Fig. 6B,C).

In addition to morphological similarity to other zooplankton groups, previously undocumented larval behaviors temporarily increase larval similarity to the abundant gelatinous zooplankton. Larval flatfishes and leptocephalus larvae were detected in a curled posture that makes them appear similar to gelatinous zooplankton. On the rare occasion that live larvae with intact long fin rays have been observed in situ, they tend to remain motionless (Govoni et al. 1984), similar to drifting gelatinous zooplankton. Our results also quantified the orientation behavior of larval fishes, demonstrating a significant trend of increasing vertical orientation with increasing larval fish aspect ratio. Chaetognaths tended to orient vertically, with some variation likely due to their in situ positioning within the imaged parcel of water relative to the camera.

While many larval fishes showed strong morphological and behavioral similarity to gelatinous zooplankton, the mimicry is not perfect; however, this is expected based on evolutionary theory. When a model is costly to attack and mimics are relatively rare (both true with respect to gelatinous zooplank-

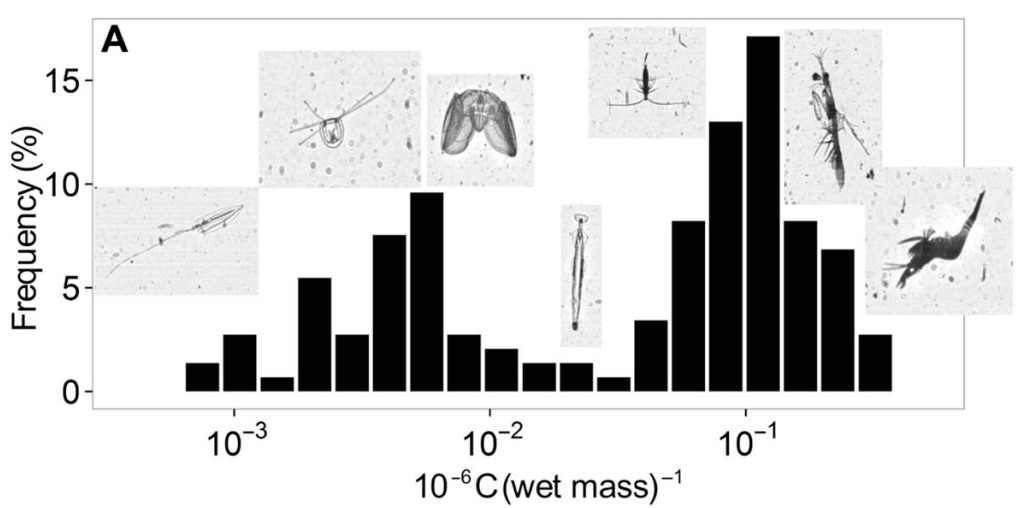

B

Larval fish appearance

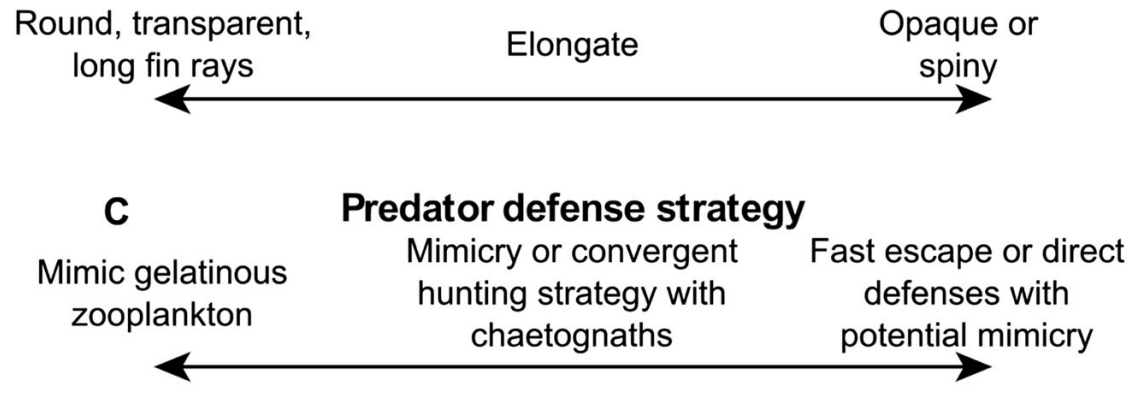

Fig. 6. Conceptual diagram showing the range of morphologies and predator defenses in larval fishes and zooplankton. (A) Histogram (data from Kiørboe 2013; reused with permission) showing bimodal distribution of carbon content per unit wet biomass. The $y$-axis refers to the percentage of organisms maintaining a particular carbon content per unit wet biomass ratio. The $x$-axis depicts the ratio of carbon mass per unit wet mass. Images of zooplankton taken with the ISIIS are listed from left to right: calycophoran siphonophore, hydromedusa, lobate ctenophore (Ocyropsis spp.), chaetognath (Sagitta spp.), copepod, mantis shrimp larva, and euphausiid shrimp. (B) Range of larval morphologies corresponding to part A. (C) Range of larval defense strategies corresponding to part A 
ton and larval fishes), there is little selection for an exact mimic (Sherratt 2002). When a potential mimic is exposed to many different models (as is the case in the marine zooplankton), the optimal strategy is to evolve into an intermediate 'Jack-of-all-trades' mimic that doesn't closely resemble any model (Sherratt 2002). This suggests the long fin rays with small swellings that are found throughout different larval fish families evolved to allow larvae to resemble a wide range of gelatinous zooplankton. A variety of predators with differing selective pressures or deficient cognitive abilities also favors imperfect mimicry (Kikuchi \& Pfennig 2010, Pekár et al. 2011). Studies mostly on terrestrial animals show that predators often use one or a few features to categorize prey as suitable or unsuitable, and predators may sequentially process stimuli, allowing for imperfect mimics to receive protection (Aronsson \& Gamberale-Stille 2008, Gamberale-Stille et al. 2012). It must be considered, however, that several different explanations often apply to cases of imperfect mimicry (Kikuchi \& Pfennig 2013). Counterintuitively, when a mimic is exposed to many models equally, it is advantageous to closely mimic the least noxious model organism because only a slight resemblance to highly noxious models confers a survival benefit (Sherratt 2002). This could be the case with the leptocephalus larva that closely mimics a non-noxious cestid ctenophore. Leptocephalus larvae have exceptionally long larval phases during which they likely encounter many models and co-occur with the open ocean cestid ctenophores, making the resemblance to these nonnoxious models beneficial. The leptocephalus larvae also have flexibility of their mimicry, as demonstrated by a curling behavior allowing them to resemble salps (Miller et al. 2013). This behavior was documented in the in situ plankton images for both the leptocephalus larvae and flatfishes.

The final criterion for mimicry to be a viable survival strategy is that there must be an 'umbrella' of protection, whereby even mimics with only a slight resemblance to the model receive some degree of protection (Caley \& Schluter 2003). Our simulations demonstrate that metabolically costly traits can evolve because predation mortality provides a strong selective pressure on extremely large larval populations. This suggests that the larval stage is a potentially overlooked evolutionary bottleneck for virtually all marine species, which can lead to extremely diverse morphologies and behaviors that can involve Batesian mimicry. Such traits may not always be beneficial to the adult population. In other words, selection may occur at the larval phase first, with follow- up adult selection optimizing the organisms to their environment across several life stages with differing ecological requirements. Empirical data supporting the 'umbrella of protection' criterion is a critical gap in the evidence supporting the larval mimicry hypothesis.

\section{Consequences of larval mimicry for fish early life history}

Recent field-derived measurements of larval mortality suggest that mortality rates are less extreme than previously thought (White et al. 2014), and mimicry could provide a mechanism for reducing mortality. Mimicry in the larval phase may be an advantage for populations that experience high environmental variability, which is characteristic of most ocean ecosystems. More specifically, mimicry could be more common in species that require larval transport to a particular benthic habitat, allowing them to delay settlement until that habitat is reached. This is potentially exemplified by some coral reef fishes that have conspicuous larvae that appear to mimic lionfish (Leis et al. 2015). As recent research has shown that fish species with seasonal spawning aggregations have limited connectivity pathways (Kough \& Paris 2015), we may expect these species to have larvae that are better adapted to survive in the plankton through the use of mimicry (e.g. family Serranidae) compared to species with protracted spawning periods. If the dispersal pathways are limited both temporally and spatially, then for the population to sustain itself, the larvae must be equipped with traits that improve larval survival rates (e.g. mimicry or spination). Protracted spawners will reproduce numerous times in a given season; therefore, it may be more evolutionarily favorable for the population not to invest in larval defenses and simply to rely on occasionally beneficial environmental conditions (e.g. food concentrations, currents, temperatures, or other parameters) to sustain the population.

With the abundance of these unpalatable models and visual predators, mimicry has the potential to be widespread, particularly in tropical environments where light penetration is deep, and larval survival appears to be less associated with large-scale seasonal productivity that characterizes temperate marine ecosystems (Llopiz 2013). For marine fish larvae, there seem to be 3 approaches to surviving encounters with predators: (1) extend many parts of the body, which reduces swimming escape ability but improves mimicry of less palatable gelatinous zoo- 
plankton; (2) have an elongate body shape and reside in the water column vertically to reduce crosssectional area and mimic chaetognaths, which probably has benefits for stalking prey and avoiding detection by predators above and below; or (3) develop spines and direct defenses against predation similar to some crustacean zooplankton. The degree of success between these 3 strategies will likely depend on the dominant predator taxa, their behavioral response to prey, and requirements of the larvae to complete their life cycle. For example, larvae that utilize mimicry may have hindered swimming escape responses, but they may still use swimming to orient, vertically migrate, and bias transport to settlement areas (Paris \& Cowen 2004, Irisson et al. 2010, Leis et al. 2011, Staaterman et al. 2012) Further research is required to determine the energetic and ecological trade-offs of each survival strategy, and the frequency of use by fish larvae in the marine environment.

\section{Future research}

The results of this study emphasize the need to accurately describe marine food webs and understand predator-prey interactions on the scale of individuals. Although the ubiquity of elaborate larval forms suggests an overall survival benefit, the advantage of mimicry for individuals depends on the fine-scale spatiotemporal distributions of the mimics, models, and predators. Future work to address the larval mimicry hypothesis needs to focus on 3 main areas: (1) the fine-scale gelatinous zooplankton environment experienced by larval fishes; (2) the changes in larval fish behavior when predators are present (both depth distribution and body positioning); and (3) cognitive abilities of larval fish predators. Through the use of imaging technology, rapid progress is being made on descriptions of the fine-scale environment, particularly with regards to the fragile gelatinous organisms encountered by larval fishes in the euphotic zone (Greer et al. 2014, 2015, Luo et al. 2014).

The next steps to determine the validity of the larval mimicry hypothesis will come from controlled experiments that can elucidate the behaviors driving the interactions that occur on these fine scales. Small fishes (relevant visual predators to larval fishes) can learn that certain colors are unpalatable (Kerfoot et al. 1980), but their response to shapes, texture, or movement is poorly described. One can imagine a controlled aquarium experiment where predators, larvae, and artificial gelatinous zooplankton are allowed to interact, and mortality rates on larvae are measured with different types and abundances of these 'models'. Through varying the artificial gelatinous zooplankton resemblance to the larval fish, a researcher could identify visual cues for palatability and quantify extent of the 'umbrella of protection' under different circumstances. Based on the widespread presence of extended fin rays in a variety of larval fishes, we hypothesize that these conspicuous morphological features are fixated upon by fish predators as a mental 'shortcut' to determine palatability. If the predators indeed process palatability in a sequential manner using a few features (GamberaleStille et al. 2012), the presence of fin ray extensions may be a heavily weighted cue, indicating that the prey is unpalatable or potentially noxious. Unfortunately, many of the larvae that appear to support the mimicry hypothesis based on their morphology are currently difficult or impossible to rear in the lab, so close collaboration with the aquaculture community may be required to obtain adequate numbers of larvae for these kinds of experiments.

With the impacts of climate change and environmental degradation, the future oceans may become dominated by gelatinous zooplankton (Jackson et al. 2001, Richardson et al. 2009, but also see Condon et al. 2012), creating a strong incentive to understand their interactions with different components of marine ecosystems, particularly fishes (Purcell \& Arai 2001). If gelatinous populations increase and mimics benefit from a higher proportion of models, larval fishes that utilize mimicry could actually experience reduced visual predation in the plankton. Mimetic accuracy also may be less necessary in the presence of an elevated number of models (Harper \& Pfennig 2007). However, increased abundances of gelatinous zooplankton could potentially reach a critical level at which larval fish mortality increases through contact predation or competition for food resources (Robinson et al. 2014). The consequences of widespread Batesian mimicry under climate change scenarios are almost impossible to predict with the complex feedback controls on marine populations, but predatorprey and top-down effects under future climate scenarios must be considered and studied in more detail.

Acknowledgements. We thank the captains and crews of the NOAA ships 'Delaware II' and 'McArthur II'. Katie Shulzitski, Esther Goldstein, and Jessica Luo assisted with field collections. Dorothy Tang assisted with the enumeration of salps and cnidarians in the Georges Bank and Stellwagen Bank datasets. Steven Litvin and Andrew Kough reviewed and provided comments on an earlier version of the manuscript. David Hall's suggestions improved various aspects of the simulation modelling. 


\section{LITERATURE CITED}

Amaoka K (1972) Studies on the larvae and juveniles of the sinistral flounders. III. Laeops kitaharae. Jpn J Ichthyol 19:154-165

Anderson JT (1988) A review of size dependent survival during pre-recruit stages of fishes in relation to recruitment. J Northwest Atl Fish Sci 8:55-66

Aronsson M, Gamberale-Stille G (2008) Domestic chicks primarily attend to colour, not pattern, when learning an aposematic coloration. Anim Behav 75:417-423

Bailey KM, Houde ED (1989) Predation on eggs and larvae of marine fishes and the recruitment problem. Adv Mar Biol 25:1-83

Baldwin CC, Johnson GD (1993) Phylogeny of the Epinephelinae (Teleostei: Serranidae). Bull Mar Sci 52:240-283

Bates HW (1862) Contributions to an insect fauna of the Amazon Valley. Lepidoptera: Heliconidae. Trans Linn Soc Lond 23:495-566

Bullard SG, Hay ME (2002) Palatability of marine macroholoplankton: nematocysts, nutritional quality, and chemistry as defenses against consumers. Limnol Oceanogr 47:1456-1467

Caley MJ, Schluter D (2003) Predators favour mimicry in a tropical reef fish. Proc R Soc B 270:667-672

Cheney KL (2013) Cleaner fish coloration decreases predation risk in aggressive fangblenny mimics. Behav Ecol 24:1161-1165

Condon RH, Graham WM, Duarte CM, Pitt KA and others (2012) Questioning the rise of gelatinous zooplankton in the world's oceans. Bioscience 62:160-169

Connell SD (2000) Is there safety in numbers? Oikos 88: 527-532

Côté IM, Cheney KL (2005) Animal mimicry: choosing when to be a cleaner-fish mimic. Nature 433:211-212

> Cowen RK, Guigand CM (2008) In situ ichthyoplankton imaging system (ISIIS): system design and preliminary results. Limnol Oceanogr Methods 6:126-132

Davis ND, Myers KW, Ishida Y (1998) Caloric value of highseas salmon prey organisms and simulated salmon ocean growth and prey consumption. North Pac Anals Fish Comm Bull 1:146-162

Fraser TH, Smith MM (1974) An exterilium larval fish from South Africa with comments on its classification. Copeia 1974:886-892

- Gamberale-Stille G, Balogh ACV, Tullberg BS, Leimar O (2012) Feature saltation and the evolution of mimicry. Evolution 66:807-817

Govoni JJ (2005) Fisheries oceanography and the ecology of early life histories of fishes: a perspective over fifty years. Sci Mar 69(Suppl 1):125-137

Govoni JJ, Olney JE, Markle DF, Curtsinger WR (1984) Observations on structure and evaluation of possible functions of the vexillum in larval Carapidae (Ophidiiformes). Bull Mar Sci 34:60-70

> Greer AT, Cowen RK, Guigand CM, McManus MA, Sevadjian JC, Timmerman AHV (2013) Relationships between phytoplankton thin layers and the fine-scale vertical distributions of two trophic levels of zooplankton. J Plankton Res 35:939-956

> Greer AT, Cowen RK, Guigand CM, Hare JA, Tang D (2014) The role of internal waves in larval fish interactions with potential predators and prey. Prog Oceanogr 127:47-61

Greer AT, Cowen RK, Guigand CM, Hare JA (2015) Finescale planktonic habitat partitioning at a shelf-slope front revealed by a high-resolution imaging system. J Mar Syst 142:111-125

- Haddock SHD, Dunn CW, Pugh PR, Schnitzler CE (2005) Bioluminescent and red-fluorescent lures in a deep-sea siphonophore. Science 309:263

Hamner WM (1995) Predation, cover, and convergent evolution in epipelagic oceans. Mar Freshwat Behav Physiol 26:71-89

Hamner WM, Madin LP, Alldredge AL, Gilmer RW, Hamner PP (1975) Underwater observations of gelatinous zooplankton: sampling problems, feeding biology, and behavior. Limnol Oceanogr 20:907-917

Hare JA, Cowen RK (1997) Size, growth, development, and survival of the planktonic larvae of Pomatomus saltatrix (Pisces: Pomatomidae). Ecology 78:2415-2431

Harper GR, Pfennig DW (2007) Mimicry on the edge: Why do mimics vary in resemblance to their model in different parts of their geographical range? Proc R Soc B 274: 1955-1961

Hjort J (1914) Fluctuations in the great fisheries of northern Europe viewed in the light of biological research. Rapp P-V Reùn Cons Int Explor Mer 20:1-228

Houde ED (1987) Fish early life dynamics and recruitment variability. Am Fish Soc Symp 2:17-29

Houde ED (2002) Mortality. In: Fuiman LA, Werner RG (eds) Fishery science: the unique contributions of the early life stages. Blackwell Science, Malden, MA, p 64-87

- Huheey JE (1988) Mathematical models of mimicry. Am Nat 131:S22-S41

> Irisson JO, Paris CB, Guigand C, Planes S (2010) Vertical distribution and ontogenetic 'migration' in coral reef fish larvae. Limnol Oceanogr 55:909-919

> Jackson JBC, Kirby MX, Berger WH, Bjorndal KA and others (2001) Historical overfishing and the recent collapse of coastal ecosystems. Science 293:629-637

Johnsen S (2014) Hide and seek in the open sea: pelagic camouflage and visual countermeasures. Annu Rev Mar Sci 6:369-392

Kazemi B, Gamberale-Stille G, Leimar O (2015) Multi-trait mimicry and the relative salience of individual traits. Proc R Soc B 282:20152127

Kerfoot WC, Kellogg DL, Strickler JR (1980) Visual observations of live zooplankters: evasion, escape, and chemical defenses. In: Kerfoot WC (ed) Evolution and ecology of zooplankton communities. University Press of New England, Hanover, NH, p 10-27

Kikuchi DW, Pfennig DW (2010) Predator cognition permits imperfect coral snake mimicry. Am Nat 176:830-834

Kikuchi DW, Pfennig DW (2013) Imperfect mimicry and the limits of natural selection. Q Rev Biol 88:297-315

Kiørboe T (2008) A mechanistic approach to plankton ecology. Princeton University Press, Princeton, NJ

Kiørboe T (2013) Zooplankton body composition. Limnol Oceanogr 58:1843-1850

> Kough AS, Paris CB (2015) The influence of spawning periodicity on population connectivity. Coral Reefs 34: 753-757

> Leis JM, Siebeck UE, Dixson DL (2011) How Nemo finds home: the neuroecology of dispersal and of population connectivity in larvae of marine fishes. Integr Comp Biol 51:826-843

Leis JM, Meyer O, Hay AC, Gaither MR (2015) A coral-reef fish with large, fast, conspicuous larvae and small, cryptic adults (Teleostei: Apogonidae). Copeia 103:78-86

Llopiz JK (2013) Latitudinal and taxonomic patterns in the 
feeding ecologies of fish larvae: a literature synthesis. J Mar Syst 109-110:69-77

Luo JY, Grassian B, Tang D, Irisson JO and others (2014) Environmental drivers of the fine-scale distribution of a gelatinous zooplankton community across a mesoscale front. Mar Ecol Prog Ser 510:129-149

Mackie GO (1995) Defensive strategies in planktonic coelenterates. Mar Freshwat Behav Physiol 26:119-129

McFall-Ngai MJ (1990) Crypsis in the pelagic environment. Am Zool 30:175-188

Miller BS, Kendall AW (2009) Early life history of marine fishes. University of California Press, Berkeley, CA

Miller MJ, Norman MD, Tsukamoto K, Finn JK (2013) Evidence of mimicry of gelatinous zooplankton by anguilliform leptocephali for predator avoidance. Mar Freshwat Behav Physiol 45:375-384

Moser HG (1981) Morphological and functional aspects of marine fish larvae. In: Lasker R (ed) Marine fish larvae: morphology, ecology, and relation to fisheries. University of Washington Press, Seattle, WA, p 89-131

Nelson XJ (2014) Evolutionary implications of deception in mimicry and masquerade. Curr Zool 60:6-15

Ohman MD (1988) Behavioral responses of zooplankton to predation. Bull Mar Sci 43:530-550

Okamoto M, Ida H (2001) Description of a postflexion larva specimen of Liopropoma japonicum from off Izu Peninsula, Japan. Ichthyol Res 48:97-99

Paris CB, Cowen RK (2004) Direct evidence of a biophysical retention mechanism for coral reef fish larvae. Limnol Oceanogr 49:1964-1979

Pekár S, Jarab M, Fromhage L, Herberstein ME (2011) Is the evolution of inaccurate mimicry a result of selection by a suite of predators? A case study using myrmecomorphic spiders. Am Nat 178:124-134

Purcell JE (1980) Influence of siphonophore behavior upon their natural diets: evidence for aggressive mimicry. Science 209:1045-1047

Purcell JE, Arai MN (2001) Interactions of pelagic cnidarians and ctenophores with fish: a review. Hydrobiologia 451: $27-44$

R Core Team (2014) R: a language and environment for statistical computing. R Foundation for Statistical Computing, Vienna

Editorial responsibility: Steven Morgan,

Bodega Bay, California, USA
Randall JE (2005) A review of mimicry in marine fishes. Zool Stud 44:299-328

Rasband WS (2012) ImageJ. US National Institutes of Health. http://imagej.nih.gov/ij/

Remsen A, Hopkins TL, Samson S (2004) What you see is not what you catch: a comparison of concurrently collected net, optical plankton counter, and shadowed image particle profiling evaluation recorder data from the northeast Gulf of Mexico. Deep-Sea Res I 51:129-151

- Richardson AJ, Bakun A, Hays GC, Gibbons MJ (2009) The jellyfish joyride: causes, consequences and management responses to a more gelatinous future. Trends Ecol Evol 24:312-322

Robinson KL, Ruzicka JJ, Decker MB, Brodeur RD and others (2014) Jellyfish, forage fish, and the world's major fisheries. Oceanography (Wash DC) 27:104-115

Robison BH (1999) Shape change behavior by mesopelagic animals. Mar Freshwat Behav Physiol 32:17-25

Ruxton GD, Sherratt TN, Speed MP (2004) Avoiding attack: the evolutionary ecology of crypsis, warning signals, and mimicry. Oxford University Press, New York, NY

> Sherratt TN (2002) The evolution of imperfect mimicry. Behav Ecol 13:821-826

Staaterman E, Paris CB, Helgers J (2012) Orientation behavior in fish larvae: a missing piece to Hjort's critical period hypothesis. J Theor Biol 304:188-196

Suntsov AV (2007) Brotulotaenia (Teleostei: Ophidiiformes) larval development revisited: an apparently new type of mimetic resemblance in the epipelagic ocean. Raffles Bull Zool (Suppl 14):177-186

Webb JF (1999) Larvae in fish development and evolution. In: Hall BK, Wake MH (eds) The origin and evolution of larval forms. Academic Press, San Diego, CA, p 109-158

Weihs D, Moser HG (1981) Stalked eyes as an adaptation towards more efficient foraging in marine fish larvae. Bull Mar Sci 31:31-36

- White JW, Morgan SG, Fisher JL (2014) Planktonic larval mortality rates are lower than widely expected. Ecology 95:3344-3353

Wuenschel MJ, Jugovich AR, Hare JA (2006) Estimating the energy density of fish: the importance of ontogeny. Trans Am Fish Soc 135:379-385

Submitted: December 1, 2015; Accepted: April 27, 2016

Proofs received from author(s): May 16, 2016 